\title{
AROUSAL TIME FROM INTRAOPERATIVE SEDATION IN ADULT PATIENTS DURING SPINAL ANAESTHESIA FOR INFRAUMBILICAL SURGERIES- A COMPARISON BETWEEN DEXMEDETOMIDINE AND MIDAZOLAM
}

\author{
Sreyya Ganguly1, Subhrajyoti Chattopadhyay², Sekhar Ranjan Basu ${ }^{3}$ \\ ${ }^{1}$ Consultant Anaesthesiologist, Berhampur, Murshidabad, West Bengal. \\ ${ }^{2}$ Associate Professor, Department of Anaesthesiology, North Bengal Medical College, West Bengal. \\ 3Professor, Department of Anaesthesiology, North Bengal Medical College, West Bengal.
}

\begin{tabular}{l}
\hline ABSTRACT \\
BACKGROUND \\
Sedation increases the patient's acceptance of regional block in terms of satisfaction, comfort and amnesia. Several drugs including \\
midazolam and dexmedetomidine have been evaluated regarding onset of sedation, haemodynamic stability and patient \\
satisfaction. \\
$\quad$ This study was designed to find out any difference in the recovery pattern especially the arousal time from sedation using \\
either dexmedetomidine or midazolam infused at a variable infusion titrated to achieve a specific level of sedation.
\end{tabular}

\section{MATERIALS AND METHODS}

A total of 64 patients of ASA I and II posted for elective infraumbilical surgeries under spinal anaesthesia were randomly allocated into two groups to receive either bolus of dexmedetomidine $0.5 \mu \mathrm{g} / \mathrm{kg}$ followed by infusion at $0.5 \mu \mathrm{g} / \mathrm{kg} / \mathrm{h}(\mathrm{Group} \mathrm{A}, \mathrm{n}=32$ ) or bolus of midazolam $0.05 \mathrm{mg} / \mathrm{kg}$ followed by maintenance dose of $0.05 \mathrm{mg} / \mathrm{kg} / \mathrm{h}$ (Group B, $\mathrm{n}=32$ ) and titration until BIS score 70 was achieved; thereafter maintained between 60-70. The Observer Assessment of Alertness/Sedation (OAA/S) Scale score was assessed at Bispectral Index (BIS) Score 70 and once again at BIS 90 during recovery. Time to clinical recovery (OAA/S score 5) was noted.

\section{RESULTS}

Arousal time from sedation using dexmedetomidine was found lower compared to midazolam $(7.8 \pm 2.4$ vs. $15.67 \pm 6.3 \mathrm{~min}$., respectively, $\mathrm{P}=0.000)$. The time taken to reach $\mathrm{OAA} / \mathrm{S}$ score 5 was also found to be lower for dexmedetomidine than using midazolam (7.18 \pm 1.59 vs. $13.67 \pm 6.75$, respectively, $\mathrm{P}=0.000)$.

\section{CONCLUSION}

A shorter arousal time can be achieved using dexmedetomidine compared with midazolam when used for sedation during spinal anaesthesia, while depth of sedation was monitored continuously using BIS monitor and intermittently assessed with OAA/S score.

\section{KEYWORDS}

Bispectral Index Monitoring, Dexmedetomidine, Midazolam, Sedation, Spinal Anaesthesia.

HOW TO CITE THIS ARTICLE: Ganguly S, Chattopadhyay S, Basu SR. Arousal time from intraoperative sedation in adult patients during spinal anaesthesia for infraumbilical surgeries- A comparison between dexmedetomidine and midazolam. J. Evolution Med. Dent. Sci. 2017;6(1):46-51, DOI: 10.14260/Jemds/2017/13

\section{BACKGROUND \\ Nowadays, sedation during regional anaesthesia has become a standard protocol, not only to alleviate patient's anxiety but also to produce amnesia of the surgical procedure. ${ }^{1}$ Monitoring the depth of sedation is important to maintain a proper level of sedation as both oversedation and undersedation are detrimental to the patient.2 Various drugs like diazepam, midazolam, propofol and recently dexmedetomidine have been tried as sedatives during regional anaesthesia.}

Financial or Other, Competing Interest: None.

Submission 26-11-2016, Peer Review 19-12-2016,

Acceptance 26-12-2016, Published 02-01-2017.

Corresponding Author:

Dr. Subhrajyoti Chattopadhyay,

C/o. Mr. Satyajit Chakroborty,

Trinayani Apartment,

$2^{\text {nd }}$ Floor, Taltala,

Arabinda Pally,

Siliguri-734006, West Bengal.

E-mail: drsubhra1972@gmail.com

DOI: $10.14260 /$ jemds $/ 2017 / 13$

\section{(c) $(\mathrm{i)})$}

Midazolam, a short-acting benzodiazepine having rapid onset and offset of action, can produce anxiolysis, sedation, and amnesia during spinal anaesthesia. Dexmedetomidine, a new $\alpha 2$-adrenergic receptor agonist is now being used widely as a primary sedative anaesthetic agent during regional anaesthesia and for monitored anaesthesia care due to its sedative, hypnotic, analgesic property. ${ }^{3}$ It causes limited respiratory depression, has easy arousability.

A few studies have compared sedative effects of both the drugs in patients undergoing operation under neuraxial blockade.4-7 Only one study has compared the arousal time between the two drugs administered as a fixed infusion rate and the recovery time from sedation was not the main focus of their observation. ${ }^{7}$ This prospective randomised doubleblind study has therefore been designed to compare the arousal time from intraoperative sedation under BIS monitoring 8 using either dexmedetomidine or midazolam during spinal anaesthesia for infraumbilical surgeries. Additionally, the Observer Assessment of Alertness/Sedation (OAA/S) Scale Score ${ }^{9}$ was assessed at BIS value of 70 and 90 and were compared between the two groups. The patients' satisfaction scores between the two groups were also compared. 


\section{MATERIALS AND METHODS}

Patients of either sex (age 18 to 60 years, complying with American Society of Anesthesiologists (ASA) physical status I and II criteria, posted for elective infraumbilical operations (Surgical, gynaecological, or orthopaedic) of approximate 90 minutes duration were included in this double blinded study. Patients refusing either to accept spinal anaesthesia or to receive sedation during surgery were excluded. Patients with contraindications for spinal anaesthesia, pregnant patients, and those with cardiorespiratory diseases, psychiatric illnesses or history of allergy to study drugs were excluded from the study.

In a previous study using midazolam for sedation, the arousal time was found to be $3.5 \mathrm{~min} .{ }^{10} \mathrm{~A}$ difference of at least $3 \mathrm{~min}$. in the arousal time from sedation between the two drugs (Dexmedetomidine versus midazolam) was taken to be clinically significant. The power of study $(1-\beta)$ was set at $90 \%$ and the confidence interval was set at $95 \%(\alpha<0.05)$. Thus, the sample size was calculated to be 29 patients in each group. Expecting a 10\% dropout rate, a total of 64 patients were included in the current study.

The study commenced after approval from the Institutional Ethics Committee. The present study was registered (No. CTRI/2014/02/004376) with the 'Clinical Trial Registry of India' (www.ctri.nic.in). After proper discussion with the patient regarding the nature of the anaesthetic and sedation procedures, informed consent was taken. One large bore (18G) intravenous cannula was then established and an infusion started with warm Ringer's lactate to achieve a preload of $15 \mathrm{~mL} / \mathrm{kg}$ in 30 minutes. Under adequate monitoring, the patients were premedicated with inj. ranitidine $50 \mathrm{mg}$, inj. ondansetron $4 \mathrm{mg}$ and inj. tramadol $50 \mathrm{mg}$ IV slowly around thirty minutes before the surgery, in a side room. The patients were again thoroughly explained and counselled about the procedure. At the same time, they were also demonstrated the proper use of the 7-point 'Likertlike Verbal Rating Scale' to express their satisfaction about the quality of sedation they will receive during the intraoperative period. They were informed that this will be placed before them in the immediate post-operative period.

The patient was transferred to operating room (OR) on scheduled time and multichannel monitor (Non-invasive blood pressure, electrocardiogram, and pulse oximeter) was attached and the baseline parameters [Mean arterial pressure (MAP), heart rate (HR) and peripheral arterial oxygen saturation $\left.\left(\mathrm{SpO}_{2}\right)\right]$ were monitored and the observed values were recorded. The anaesthesia machine with resuscitating facilities was kept ready for use in emergency. The forehead and both the temples of the patient were cleaned with spirit and the 4 electrodes of BIS monitor (Aspect Medical Systems, A-2000 BIS XP model) were attached following standard recommendations.

The syringe was then loaded with the study drug (Inj. dexmedetomidine or inj. midazolam) as per the group decided by lottery method. Both the solutions being colourless and equal in amount, the blinding was easier. The infusion pump was connected with the IV line with an infusion line and a three way stop valve and was set ready for use when necessary.

The patient was placed in the left lateral decubitus position. Spinal anaesthesia was given with 2.5 to $3.0 \mathrm{~mL}$ of hyperbaric bupivacaine $(0.5 \%)$ using Quincke needle (26G) at L3-L4 or L2-L3 interspinous space after aseptic precaution and local anaesthetic infiltration. After positioning the patient in recumbent supine posture, BIS monitoring was started. After establishment of the sensory block up to the T6 level, sedation as appropriate for the group was initiated. At this point, the vital parameters were recorded once again. Subsequently, the surgery was started.

The sedative drug was prepared by an anaesthesiologist who did not participate in patient management or data collection later on. The study drug was prepared using either dexmedetomidine $1 \mu \mathrm{g} / \mathrm{kg}$ or midazolam $0.1 \mathrm{mg} / \mathrm{kg}$ with addition of normal saline up to a total volume of $20 \mathrm{~mL}$. This was handed over to the attending anaesthesiologist for administration as per study protocol which allowed a patient to receive either injection (inj.) dexmedetomidine (Group A) or inj. midazolam (Group B) as per randomisation. The observer was unaware of the group allocation regarding which specific drug is being infused to the patient. The patient who was receiving the drug was also not aware of the drug. Thus, the study has been made double blind. Allocation concealment was done by 'sealed opaque envelope' method.

The $20 \mathrm{~mL}$ solution of study drug was infused at a rate of $60 \mathrm{~mL} / \mathrm{h}$ for the first $10 \mathrm{~min}$. followed by infusion at a rate of $10 \mathrm{~mL} / \mathrm{h}$. This had led to administration of either dexmedetomidine loading dose $0.5 \mu \mathrm{g} / \mathrm{kg}$ followed by maintenance with $0.5 \mu \mathrm{g} / \mathrm{kg} / \mathrm{h}$ or midazolam loading dose $0.05 \mathrm{mg} / \mathrm{kg}$ followed by maintenance with $0.05 \mathrm{mg} / \mathrm{kg} / \mathrm{h}$ ) The infusion was continued until a BIS score of 70 was reached. At this point, the Observer Assessment of Alertness/Sedation (OAA/S) scale score ${ }^{11}$ was also noted as a clinical measurement of the patient's sedation status. The infusion was then titrated to maintain the BIS score between 65 and 70.

Time needed for onset of sedation, defined as the time from starting the infusion of study drug till a BIS score of 70 is achieved, was recorded. The OAA/S scale score (Clinical sedation) at this level was also noted. MAP was measured continually at 5 minutes interval and the other parameters (HR, $\mathrm{SpO}_{2}$, and respiratory rate) were monitored continuously throughout the surgery. All parameters were documented at 10 minutes intervals till arousal of the patient. Infusion was stopped approximately 5 minutes before the end of surgery to facilitate lesser stay in the operating room.

BIS was monitored continuously from after the induction of spinal anaesthesia all through the operation up to the arousal of the patient. The arousal of the patient was taken to be equivalent to achievement of a BIS level of 90. The 'arousal time from sedation' (Primary outcome) was recorded. It was defined as time from stoppage of study drug infusion till a BIS score of 90 is achieved. It indicates the time taken for recovery from the effect of sedation administered. At this point, i.e. when the patient achieves BIS score of 90, the patient's sedation status was also evaluated clinically using $\mathrm{OAA} / \mathrm{S}$ scale score. Here again, the time to reach the OAA/S scale score of 5 i.e., the 'time to clinical recovery' was noted. It was calculated as the time from stop of study drug infusion up to the time at which the patient is fully awake. The patient's satisfaction with the sedation was assessed by the 7 point 'Likert-like Verbal Rating Scale' with questions like 'Where will you put your experience with this sedation on this scale?' in a language with which the patient is conversant, at a point of time when the patient is deemed to have a mental state suitable for communication.

Hypotension was defined in the study as fall of the MAP below $25 \%$ of the baseline MAP. Bradycardia was taken to be 
a heart rate less than 50 beats per minute and hypoxaemia (Desaturation) was defined as a $\mathrm{SpO}_{2}$ below 90. The incidences of such adverse events like hypotension, bradycardia and desaturation were recorded. Also, the incidence of nausea and vomiting was noted independently. The number of such incidences was noted. Hypotension was managed with IV $3 \mathrm{mg}$ boluses of inj. mephentermine, repeated as required. Bradycardia, if symptomatic, was treated with inj. atropine $0.6 \mathrm{mg}$ IV. Hypoxaemia was treated with oxygen inhalation by simple oxygen mask at 4-6 L/min. Nausea or vomiting was treated with inj. ondansetron in a dose of $4 \mathrm{mg}$ IV.

Data were charted on the Excel Workbook (Microsoft Office Home and Student 2007, Microsoft Corporation, One Microsoft Way Redmond, WA 98052 USA) and were analysed using Statistical Package for the Social Sciences (SPSS) for Windows (Version 12.0, SPSS Inc., Chicago, IL, USA). P $<0.05$ was considered as statistically significant.

\section{RESULTS}

The study spanned from June 2013 to May 2014. As all patients complied with the study, the data from 64 patients were available for analysis. Patients in both the groups are found to be comparable in respect of age, weight, height, sex distribution, and the ASA physical status and duration of surgery (Table-1). The intraoperative haemodynamic parameters (Mean arterial pressure and heart rate) were compared at various time points and are depicted in the figure 1 and 2 . There was significant reduction in HR after 10 minutes of loading dose in the patients receiving dexmedetomidine. The arousal time from sedation i.e., time taken for recovery was significantly lower for the patients receiving dexmedetomidine (Group A) when compared with patients receiving midazolam i.e. group $\mathrm{B},(\mathrm{P}=0.000)$. The time to clinical recovery was also found to be lower for group A (Table 2). The OAA/S scores were comparable in both groups at BIS scores of 70 and 90 (Table 3). The patients' satisfaction scores on the 7-point Likert-like verbal rating scale were comparable in both the groups (Table 4).

\begin{tabular}{|c|c|c|c|}
\hline Variable & $\begin{array}{c}\text { Group A } \\
(n=32)\end{array}$ & $\begin{array}{c}\text { Group B } \\
(n=32)\end{array}$ & $\begin{array}{c}\text { P- } \\
\text { value }\end{array}$ \\
\hline Age (in years) & $37.84 \pm 11.33$ & $36.5 \pm 12.06$ & 0.648 \\
\hline Height (in cm) & $153.2 \pm 10.49$ & $154.41 \pm 11.71$ & 0.67 \\
\hline Weight (in kg) & $59.13 \pm 9.98$ & $55.63 \pm 10.28$ & 0.17 \\
\hline $\begin{array}{c}* \text { Males } \\
\text { females } \\
{[\mathrm{n}(\%)]}\end{array}$ & $\begin{array}{c}17(53.1 \%) / \\
15(46.9 \%)\end{array}$ & $\begin{array}{c}21(65.6 \%) / 11 \\
(34.4 \%)\end{array}$ & 0.45 \\
\hline $\begin{array}{c}\text { *ASA physical }^{\text {status I/II }} \\
\text { st }\end{array}$ & $\begin{array}{c}19(59.4 \%) / \\
13(40.6 \%)\end{array}$ & $\begin{array}{c}21(65.6 \%) / \\
11(34.4 \%)\end{array}$ & 0.8 \\
\hline $\begin{array}{c}\text { Duration of } \\
\text { Surgery } \\
\end{array}$ & $75.19 \pm 24.94$ & $72.69 \pm 23.42$ & 0.68 \\
\hline \multicolumn{4}{|c|}{$\begin{array}{l}\text { *Categorical data; analysis done with Chi-square test. } \\
\text { Values are expressed in n (\%). The rest are numerical data; } \\
\text { analysis done with independent sample t-test. Values are } \\
\text { expressed in mean } \pm \text { SD. } \mathrm{P}<0.05 \text { is taken to be statistically } \\
\text { significant. Group A-patients receiving inj. Dexmedetomi- } \\
\text { dine; group B- patients receiving inj. midazolam. }\end{array}$} \\
\hline \multicolumn{4}{|c|}{ Table 1. The Demographic Profile and Duration of Surgery } \\
\hline
\end{tabular}

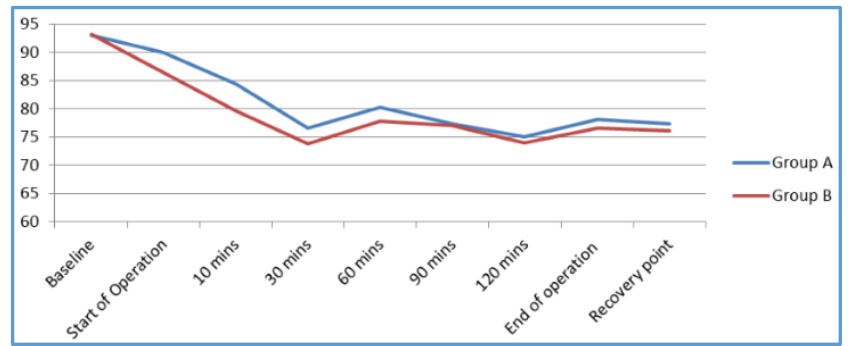

Figure 1. Mean Arterial Pressure at different points of time during Surgery. Group A- Patients Receiving Inj. Dexmedetomidine; Group $B$ - Patients receiving Inj. Midazolam

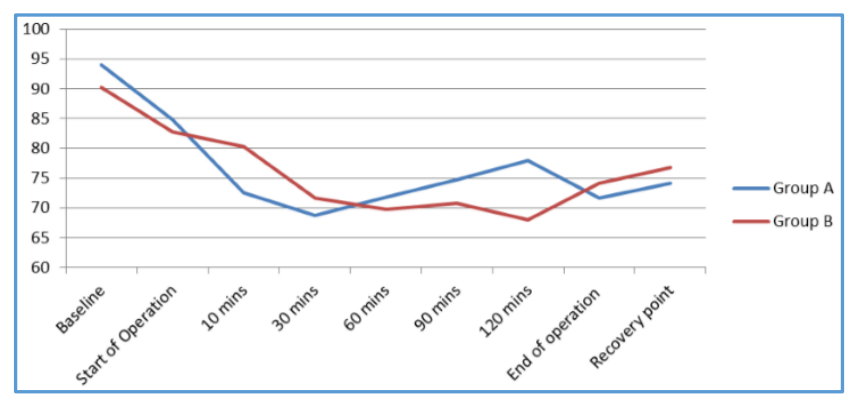

Figure 2. Heart rate at different points of time during Surgery. Group A- Patients Receiving Inj. Dexmedetomidine; Group B-Patients receiving Inj. Midazolam

\begin{tabular}{|c|c|c|c|}
\hline $\begin{array}{c}\text { Variable } \\
\text { (Time taken in minutes) }\end{array}$ & $\begin{array}{c}\text { Group A } \\
\text { (n=32) }\end{array}$ & $\begin{array}{c}\text { Group B } \\
\text { (n=32) }\end{array}$ & $\begin{array}{c}\text { P- } \\
\text { value }\end{array}$ \\
\hline $\begin{array}{c}\text { Arousal time from } \\
\text { sedation (BIS 90) }\end{array}$ & $7.8 \pm 2.4$ & $15.67 \pm 6.3$ & $<0.05$ \\
\hline $\begin{array}{c}\text { Time to clinical recovery } \\
\text { (OAA/S 5) }\end{array}$ & $7.18 \pm 1.59$ & $13.67 \pm 6.75$ & $<0.05$ \\
\hline $\begin{array}{c}\text { Numerical data; analysis done with independent sample t- } \\
\text { test. Values are expressed in mean } \pm \text { SD. P<0.05 is taken to be } \\
\text { statistically significant. Group A-patients receiving inj. } \\
\text { dexmedetomidine; group B- patients receiving inj. } \\
\text { midazolam. }\end{array}$ \\
\hline \multicolumn{3}{|c|}{ Table 2. Recovery Characteristics } \\
\hline
\end{tabular}

\begin{tabular}{|c|c|c|c|c|}
\hline \multicolumn{2}{|c|}{ Variable } & $\begin{array}{c}\text { Group A } \\
(n=32)\end{array}$ & $\begin{array}{c}\text { Group B } \\
(n=32)\end{array}$ & P-value \\
\hline \multirow{4}{*}{$\begin{array}{c}\text { OAA/S score at } \\
\text { BIS } 70\end{array}$} & OAA/S1 & $2(6.25 \%)$ & $5(6.25 \%)$ & \multirow{4}{*}{0.78} \\
\hline & OAA/S2 & $6(18.75 \%)$ & $8(25 \%)$ & \\
\hline & OAA/S3 & $23(71.88 \%)$ & $17(53.13 \%)$ & \\
\hline & OAA/S4 & $1(3.12 \%)$ & $2(6.25 \%)$ & \\
\hline \multirow{2}{*}{$\begin{array}{c}\text { OAA/S score at } \\
\text { BIS } 90\end{array}$} & OAA/S4 & 7 (21.88\%) & $8(25 \%)$ & \multirow{2}{*}{0.77} \\
\hline & OAA/S5 & $25(78.12 \%)$ & $24(75 \%)$ & \\
\hline \multicolumn{5}{|c|}{$\begin{array}{l}\text { Categorical data; analysis done with Chi-square test. Values } \\
\text { are expressed in } \mathrm{n}(\%) . \mathrm{P}<0.05 \text { is taken to be statistically } \\
\text { significant. Group A-patients receiving inj. Dexmedetomidine; } \\
\text { group B- patients receiving inj. midazolam. }\end{array}$} \\
\hline \multicolumn{5}{|c|}{ Table 3. Comparison of OAA/S Scores of both } \\
\hline
\end{tabular}




\begin{tabular}{|c|c|c|c|}
\hline Variables & $\begin{array}{c}\text { Group } \\
\mathrm{A}(\mathrm{n}=32)\end{array}$ & $\begin{array}{c}\text { Group B } \\
(n=32)\end{array}$ & P-value \\
\hline $\begin{array}{l}\text { Patient satisfaction } \\
\quad \text { score of } 5\end{array}$ & $2(6.25 \%)$ & $3(9.37 \%)$ & \multirow{3}{*}{0.83} \\
\hline $\begin{array}{l}\text { Patient satisfaction } \\
\text { score of } 6\end{array}$ & $9(28.12 \%)$ & $10(31.25 \%)$ & \\
\hline $\begin{array}{l}\text { Patient satisfaction } \\
\text { score of } 7\end{array}$ & $21(65.62 \%)$ & $19(59.37 \%)$ & \\
\hline \multicolumn{4}{|c|}{$\begin{array}{l}\text { Categorical data; analysis done with Chi-square test. Values are } \\
\text { expressed in } \mathrm{n}(\%) . \mathrm{P}<0.05 \text { is taken to be statistically significant } \\
\text { Group A-patients receiving inj. dexmedetomidine; group B- } \\
\text { patients receiving inj. midazolam. }\end{array}$} \\
\hline \multicolumn{4}{|c|}{$\begin{array}{l}\text { Table 4. Patients' Satisfaction Score on the } \\
\text { 7-point Likert-like Verbal rating Scale }\end{array}$} \\
\hline
\end{tabular}

\section{DISCUSSION}

In the present study, shorter arousal time from sedation was found using dexmedetomidine compared with midazolam (7.8 \pm 2.4 vs. $15.67 \pm 6.3 \mathrm{~min}$.); the difference being statistically significant. Arousal times were not evaluated about dexmedetomidine and midazolam in any previous studies except Liang et al7 who found no significant difference. They used either dexmedetomidine $0.5 \mu \mathrm{g} / \mathrm{kg}$ as loading dose infused over 10 minutes followed by infusion of $0.5 \mu \mathrm{g} / \mathrm{kg} / \mathrm{h}$ or midazolam loading dose $0.05 \mathrm{mg} / \mathrm{kg}$ infused over 10 minutes, followed by infusions $0.05 \mathrm{mg} / \mathrm{kg} / \mathrm{h}$, respectively. This regime achieved excellent sedation [Ramsay Sedation Scale (RSS) score of 3-5] in patients undergoing gynaecologic surgery under epidural anaesthesia. On achieving the targeted RSS scores 3-5, surgery was started. The infusion was run at a fixed rate $(10 \mathrm{~mL} / \mathrm{h})$ rather than titration and was stopped after the full $20 \mathrm{~mL}$ had been given. In another study, Celik et $\mathrm{al}^{4}$ used $1 \mu \mathrm{g} / \mathrm{kg}$ dexmedetomidine and 0.04 $\mathrm{mg} / \mathrm{kg}$ midazolam as intravenous loading dose via a syringe infusion pump over a 10-minute period, followed by 0.5 $\mu \mathrm{g} / \mathrm{kg} / \mathrm{h}$ of dexmedetomidine and $0.04 \mathrm{mg} / \mathrm{kg} / \mathrm{h}$ of midazolam as continuous infusion. In the present study, the same loading and infusion dosage regime of Liang et al was followed, but the infusion was titrated to keep the BIS between 60 and 70 . The infusion was stopped at the completion of skin closure instead of completion of the infusate.

BIS values of $\leq 60$ have been associated with a low probability of recall and a high probability of unresponsiveness during surgery under general anaesthesia. ${ }^{12}$ It is already established that persistently low BIS value increases the long-term mortality. ${ }^{13}$ BIS values between 65 and 85 have been recommended for sedation while values between 45 and 60 have been recommended for general anaesthesia. ${ }^{14}$ It has been stated that a BIS reading of 70-80 corresponds with a clinical state where patient is able to respond to 'loud verbal, limited tactile' stimulation and BIS score of 60-70 corresponds with a clinical state where patient is responsive to 'loud verbal and more intense tactile' stimulation. Hence, in the present study infusions were titrated to maintain sedation at BIS values between 60 to 70 .

The OAA/S scale score of 3 was found more in patients receiving dexmedetomidine $(71.3 \%)$ as compared to those receiving midazolam (53\%) with same BIS value of 70 . The main criterion (i.e., responsiveness) in OAA/S scale score of 3 is 'Responds after calling loudly or repeatedly' which corresponds approximately with BIS score of 70. Thus,
'OAA/S scale score 3' level is sufficient deep to allow a procedure smoothly without endangering the patient.15,16 Monitoring and titrating sedation based on OAA/S scale alone may not always be correct in dexmedetomidine sedation. The instrumental monitoring is warranted besides clinical monitoring as there are differences in the achieved level of clinical sedation using two drugs. Liang et al7 found that at comparable clinical scoring (RSS scale score of 3, arousable and shallow sedation), about two third (68\%) of recorded BIS values were lower (Between 40-60) with dexmedetomidine sedation than with midazolam. Celik et $\mathrm{al}^{4}$ also found that RSS were significantly higher in midazolam group during the intraoperative period thereby dose reduction of the drug was required in 16 out of 30 patients in midazolam group while only one out of 30 patients in dexmedetomidine group required dose adjustment. Low BIS values at any given RSS score do not indicate that BIS is wrong, rather that the characteristics of the two drugs differ substantially and that BIS values need to be interpreted in context. 4

Assessment of sedation level with OAA/S scale scoring has some disadvantages. First, it requires frequent patient stimulation and interaction, which may alter patient's sedative status. Second, subjective error can occur while labelling one level of sedation. Third, clinical assessment (OAA/S scoring) may show lighter sedation than the actual sedation level manifested by objective tools (BIS). Patient may get further dose of sedative if the level of sedation is monitored clinically alone. This may lead to further suppression of BIS index. Fourth, continuous assessment of sedation is not possible as OAA/S score denotes the level of sedation at that particular time. In contrast with intermittent assessment of sedation, the BIS-guided continuous assessment of cortical EEG activity renders the sedation management better and safer. ${ }^{17}$ Clinical assessments were done at BIS score 70 and BIS score 90 to have an idea of clinical level of sedation only at those two points of time. Hence, continuous BIS monitoring and intermittent clinical evaluation of sedation level is better to get acquainted of the sedation properties of different drugs.

The results of different studies thus indicate that the calibration for BIS differs with dexmedetomidine and other drugs. Literature indicates that BIS values do depend on the specific sedative. This is also supported by the fact that ketamine paradoxically increases BIS despite a deep clinical level of hypnosis.18 Recent evidence suggests that loss and return of consciousness are mediated by different neural pathways, and that activity in orexinergic neurons is associated with return (but not loss) of consciousness. ${ }^{19}$ Dexmedetomidine acts on sleep pathways, but does not inhibit activity in orexinergic neurons, which is probably why it causes arousable sedation. ${ }^{20}$ The major site of noradrenergic innervation in the brain with the highest concentration of presynaptic $\alpha_{2}$-adrenergic receptors is the locus caeruleus, which is responsible for arousal, sleep, and anxiety. Dexmedetomidine acts at the locus caeruleus areas but does not involve the GABA receptors. Consequently, dexmedetomidine provides a sedation that resembles natural sleep without cognitive impairment. ${ }^{21}$ As a result, despite the 120-minute elimination half-life of dexmedetomidine, patients may be easily awakened by verbal stimulation without stopping the drug infusion. 22 
Further study is required on whether dexmedetomidine has an effect on BIS itself, and the possible dose-dependent difference. The sedation produced by dexmedetomidine differs from other sedatives, as patients may be easily aroused and remain cooperative. ${ }^{23}$ In contrast, the concentration of midazolam in brain tissue has an initial phase of rapid decrease due to redistribution which is followed by a slower phase resulting from metabolism of the drug. Midazolam on metabolism in the liver produces an active metabolite, 1-hydroxy midazolam, which may be responsible for its delayed offset of action. The emergence time from sedation may thus depend on the total dose of midazolam infused as the metabolite accumulates on prolonged infusion. The recovery time after use of around 10 mg intravenous midazolam has been reported to extend to 15 minutes and beyond. ${ }^{24}$

After infusion of dexmedetomidine or midazolam, blood pressure, heart rate and cardiac output decreases slightly. Dexmedetomidine can cause an increase in arterial pressure upon rapid bolus infusion. In the current study, no significant incidence of hypotension noted in both the groups. But the dexmedetomidine patients in this study had a significant reduction in HR which occurred most commonly during a bolus or within 10 minutes of the starting of the infusion. This finding could be due to following reasons: 1) lower basal HR from increased vagal tone; 2) the baroreceptor response of high vascular tone that occurs with the bolus; or 3) high doses and decreased circulating levels of norepinephrine. ${ }^{25}$ Thus, effects of dexmedetomidine on the cardiovascular system may be beneficial in high risk patients, so this drug can be better than midazolam in this population, but it should be used with caution in patients with bradycardia.

The present study was conducted in ASA I-II patients; results may well differ in patients with some confounding diseases or in critical care setting. Target controlled infusion was not possible owing to feasibility ground. Placebocontrolled study was not done as it would be unethical to deny sedation in one group of patients.

\section{CONCLUSION}

Dexmedetomidine can be a better alternative to midazolam in terms of shorter arousal time from sedation during spinal anaesthesia, while the depth of sedation is continuously monitored using BIS monitor.

\section{REFERENCES}

[1] Brown DL. Spinal, epidural, and caudal anesthesia. In: Miller RD, (ed.) Miller's anesthesia. $7^{\text {th }}$ edn. Philadelphia: Churchill Livingstone Elsevier 2010:161227.

[2] Gurudatt C. Sedation in intensive care unit patients: assessment and awareness. Indian $\mathrm{J}$ Anaesth 2011;55(6):553-5.

[3] Candiotti KA, Bergese SD, Bokesch PM, et al. Monitored anesthesia care with dexmedetomidine: a prospective, randomized, double-blind, multicenter trial. Anesth Analg 2010;110(1):47-56.

[4] Celik M, Koltka N, Cevik B, et al. Intraoperative sedation during epidural anesthesia: dexmedetomidine vs midazolam. The Internet Journal of Anesthesiology $2007 ; 17(2)$.
[5] Kaya FN, Yavascaoglu B, Turker G, et al. Intravenous dexmedetomidine, but not midazolam, prolongs bupivacaine spinal anesthesia. Can J Anesth 2010;57(1):39-45.

[6] Korkmaz M, Gurbet A, Şahin Ş, et al. Comparison of the sedative effects of midazolam and dexmedetomidine during regional anaesthesia. Dicle Med J 2011;38(2):148-54.

[7] Liang Y, Gu M, Wang S, et al. A comparison of dexmedetomidine and midazolam for sedation in gynecologic surgery under epidural anesthesia. J Curr Surg 2011;1(1):12-8.

[8] Sinha PK, Koshy T. Monitoring devices for measuring the depth of anaesthesia-an overview. Indian J Anaesth 2007;51(5):365-81.

[9] Ho"hener D, Blumenthal S, Borgeat A. Sedation and regional anaesthesia in the adult patient. Br J Anaesth 2008;100(1):8-16.

[10] Yaddanapudi S, Batra YK, Balagopal A, et al. Sedation in patients above 60 years of age undergoing urological surgery under spinal anaesthesia: comparison of propofol and midazolam infusions. J Postgrad Med 2007;53(3):171-5.

[11] Chernik DA, Gillings D, Laine $H$, et al. Validity and reliability of the observer's assessment of alertness/sedation scale: study with intravenous midazolam. J Clin Psycho Pharmacol 1990;10(4):24451.

[12] Mansour EE. BIS guided evaluation of dexmedetomidine vs midazolam as anaesthetic adjuncts in off-pump coronary artery bypass surgery (OPCAB). Saudi J Anaesth 2009;3(1):7-14.

[13] Leslie K, Short TG. Low bispectral index values and death: the unresolved causality dilemma. Anesth Analg 2011;113(3):660-3.

[14] Johansen JW. Update on bispectral index monitoring. Best Prac Res Clin Anaesthesiol 2006;20(1):81-99.

[15] Chisholm CJ, Zurica J, Mironov D, et al. Comparison of electrophysiologic monitors with clinical assessment of level of sedation. Mayo Clin Proc 2006;81(1):46-52.

[16] Park KS, Hur EJ, Han KW, et al. Bispectral index does not correlate with observer assessment of alertness and sedation scores during $0.5 \%$ bupivacaine epidural anesthesia with nitrous oxide sedation. Anesth Analg 2006;103(2):385-9.

[17] Tschopp JM, Purek L, Frey JG, et al. Titrated sedation with propofol for medical thoracoscopy: a feasibility and safety study. Respiration 2011;82(5):451-7.

[18] Hans P, Dewandre PY, Brichant JF, et al. Comparative effects of ketamine on bispectral index and spectral entropy of the electroencephalogram under sevoflurane anaesthesia. Br J Anaesth 2005;94(3):336-40.

[19] Kelz MB, Sun Y, Chen J, et al. An essential role for orexins in emergence from general anaesthesia. Proc Natl Acad Sci USA 2008;105(4):1309-14.

[20] Nelson LE, Lu J, Guo T, et al. The alpha2-adrenoceptor agonist dexmedetomidine converges on an endogenous sleep-promoting pathway to exert its sedative effects. Anesthesiology 2003;98(2):428-36. 
[21] Shen SL, Zheng JY, Zhang J, et al. Comparison of dexmedetomidine and propofol for conscious sedation in awake craniotomy: a prospective, double-blind, randomized, and controlled clinical trial. Ann Pharmacother 2013;47(11):1391-9.

[22] Elhakim M, Abdelhamid D, Abdelfattach H, et al. Effect of epidural dexmedetomidine on intraoperative awareness and post-operative pain after one-lung ventilation. Acta Anaesthesiol Scand 2010;54(6):703-9.
[23] Ustun Y, Gunduz M, Erdogan 0, et al. Dexmedetomidine versus midazolam in outpatient third molar surgery. J Oral Maxillofac Surg 2006;64(9):1353-8.

[24] Reeves JG, Glass P, Lubarsky DA, et al. Intravenous anesthetics. In: Miller RD, edtr. Miller's anesthesia. Philadelphia: Churchill Livingstone Elsevier 2010:71941.

[25] Jorden VS, Pousman RM, Sanford MM, et al. Dexmedetomidine overdose in the perioperative setting. Ann Pharmacother 2004;38(5):803-7. 